\title{
Synthesis of Lamellar mesostructured Phenylene-Bridged Periodic Mesoporous Organosilicas (PMO) templated by PolyIon Complex (PIC) micelles
}

\author{
Albane BIRAULT ${ }^{1 *}$, Emilie MOLINA ${ }^{1}$, Carole CARCEL $^{1}$, John BARTLETT ${ }^{2 *}$, Nathalie MARCOTTE ${ }^{1}$, Guillaume TOQUER $^{3}$, \\ Patrick LACROIX-DESMAZES ${ }^{1}$, Corine GERARDIN ${ }^{1 *}$, Michel WONG CHI MAN ${ }^{1}$ \\ ${ }^{1}$ ICGM, Univ Montpellier, CNRS, ENSCM, Montpellier, France \\ ${ }^{2}$ Faculty of Science, Health, Education and Engineering, University of the Sunshine Coast, 90 Sippy Downs Dr, Sippy Downs QLD \\ 4556, AUSTRALIA
}

${ }^{3}$ Institut de Chimie Séparative de Marcoule UMR 5257 CEA-CNRS-ENSCM-UM, BP17171, 30207 Bagnols sur Cèze, France

*abirault@enscm.fr; jbartlett@usc.edu.au; corine.gerardin@enscm.fr

\section{Highlights:}

- Phenylene-bridged PMO structured by polyion complex micelles

- The PMO demonstrated lamellar mesostructure with inter-lamellae distance of $15 \mathrm{~nm}$

- Molecular-scale $(\mathrm{d}=7.6 \AA)$ structural periodicity demonstrated

\begin{abstract}
:
Periodic mesoporous organosilicas (PMOs), obtained by the surfactant-mediated hydrolysis-condensation of bridged organosilanes, combine versatile organic functionalities with advantages of a stable inorganic framework. Here, we introduce a novel synthesis of lamellar mesostructured phenylene-bridged PMOs templated by polyion complex (PIC) micelles (PICPMOs). The micelles assemble by electrostatic interactions between oppositely charged polyelectrolytes, with one being part of a double hydrophilic block copolymer (DHBC), and the other being a polybase oligochitosan (OC). The PICPMO material was characterized by a range of techniques, including TEM, IR spectroscopy, SAXS, TGA and elemental analysis, which indicates that the material exhibits long-range ordering with an inter-lamellae distance of around $15 \mathrm{~nm}$. Advantages of the synthetic approach developed, together with potential applications of the PICPMOs, are discussed.
\end{abstract}

\section{Graphical Abstract:}

Scheme 1. One pot process in water, at RT and under mild pH for structuring materials using polyionic micellar assemblies.

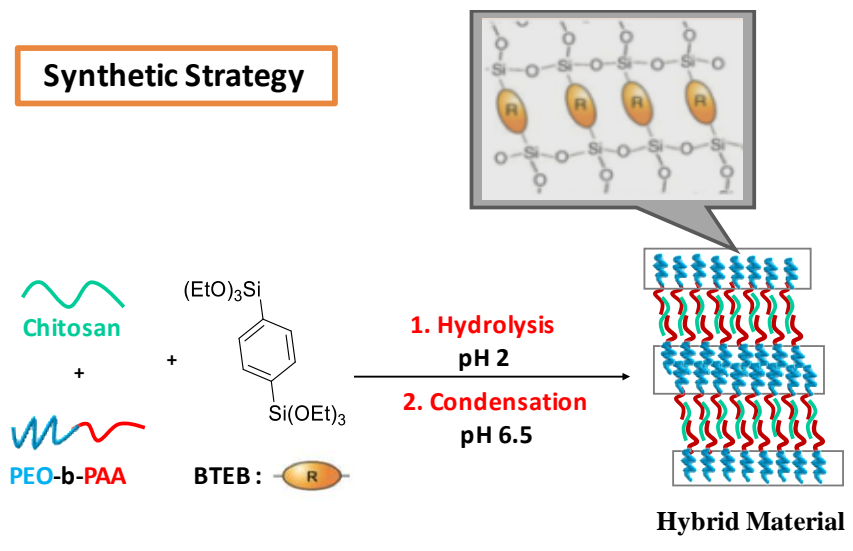

Keywords: Hybrid material / PMO / Polyion Complex Micelles.

\section{Introduction}

Periodic mesoporous organosilicas (PMOs) have been an area of intensive research since the pioneering works of Inagaki, Ozin, and Stein in 1999 [1-3] and are characterized by the homogeneous incorporation of organic functions directly into the walls of silylated matrices. They offer versatile approaches for modulating the properties of materials by, for example, adjusting the polarity or by developing specific reaction sites that are distributed on the nanoscale. The wide range of functional groups available, together with their thermal stability, lead to potential applications in such fields as gas adsorption, catalysis, electronics, drug delivery, etc.[4-6] Standard PMO syntheses, using alkylammonium, neutral amines and oligomeric surfactants, afford pore diameters between 2-5 nm. However, there is currently an imperative for increasing the pore size domain attainable for PMOs, because large-pore PMOs have an expanded range of potential applications, including the immobilization and encapsulation of proteins and other large molecules.[7]

To date, only a limited range of approaches for synthesizing large-pore PMOs have been reported, which typically employed either a combination of triblock copolymers with a swelling agent or a biphasic system.[4-9] However, Gerardin and coworkers have shown that polyion complex (PIC) micelles enable well-ordered silica-based mesophases to be produced. [10]. PIC micelles are composed of a double hydrophilic block copolymer (DHBC) in which the first block is a neutral poly(ethylene oxide)-based fragment capable of interacting with silica precursors, while the second block is ionizable and can complex with an oppositely-charged polybase (homopolyelectrolyte). The driving force for their formation is the entropy gain due to the release of counterions upon electrostatic complexation [11]. The advantages of using PIC micelles are numerous. In particular, PIC micelles, formed from DHBC polymers of adjustable polymer block lengths, are good candidates for preparing mesoporous organosilicas with tunable large pores, due to the possibility of easily modulating the size of the micelles by changing the block lengths. Moreover, PIC micelles offer the advantage of bringing functionality to the material, for example through the use of drugs as micellization agents $[12,13]$. Until now, only pure silica (generated from silica precursors such as TEOS) has been prepared via this method, typically leading to mesoporous materials with pore sizes ranging from $\sim 3$ to $10 \mathrm{~nm}$. With the goal of preparing organofunctional hybrid materials, we have investigated the use of bridged organosilanes as precursors to develop new PMO (herein referred to as PICPMO). 
In this paper, we present the first results demonstrating the use of PIC micelles as structuring agent for producing ordered mesostructured PICPMO materials that will lead to new opportunities for preparing larger pore PMO materials or drugcontaining PMOs. The materials produced are lamellar mesostructured phenylene-bridged mesoporous organosilicas, with a relatively large inter-lamellae distance. We have chosen to incorporate phenyl groups into the silylated matrix by using 1,4-bis(triethoxysilyl)benzene (BTEB) as precursor. The selfstructuring of phenyl groups based on $\pi$-stacking interactions provides high thermal and hydrothermal stability.[14] Moreover, the incorporation of phenylene functions modulates the polarity of the material and provides the possibility of further modifications, including bromination or sulfonation.[14,15] Although there have been several reports of the use of PEObased surfactants such as pluronics for producing BTEB-based PMOs, to the best of our knowledge this is the first time that PIC micelles have been employed as structure-directing agents in such systems. [16-18]

\section{Experimental}

\subsection{Materials}

All solvents were dried using an MB SPS-800 apparatus. Tertbutyl acrylate (tBuA, Aldrich, 98\%) was stirred over $\mathrm{CaH}_{2}$ for two hours and then purified by vacuum distillation. $\alpha$-methoxy$\omega$-hydroxy-poly(ethylene oxide) (PEO) with $\mathrm{M}_{\mathrm{w}}=5000 \mathrm{~g} \cdot \mathrm{mol}^{-1}$ (Aldrich) was dried by heteroazeotropic distillation in toluene overnight to remove any trace of water. $\mathrm{CuBr}_{2}$ (Aldrich, $98 \%$ ) was purified by stirring with glacial acetic acid; after filtration, it was washed with absolute ethanol and diethyl ether. 1,1,1,1,7,10,10-hexamethyltriethylenetetramine (HMTETA, Aldrich, $97 \%$ ), trifluoroacetic acid (Aldrich, $99 \%$ ), trimethylamine (Aldrich, 99\%), 2-bromoisobutyryl bromide (Aldrich, $98 \%$ ), acetone (99.5\%), DOWEX Marathon MSC H resin (Aldrich), neutral alumina $\left(\mathrm{Al}_{2} \mathrm{O}_{3}, 80-110 \mu \mathrm{m}, 155 \mathrm{~m}^{2} \cdot \mathrm{g}^{-1}\right.$, Aldrich), magnesium powder (Aldrich, 99\%), 1,4dibromobenzene (ACROS Organics, 99\%), 1,2-dibromoethane (Aldrich, 98\%), TEOS (Aldrich, 98\%), hydrochloric acid (37\%, Aldrich), $\mathrm{NaOH}$ pellets (Aldrich, 99.99\%) and absolute EtOH (Aldrich, 99.8\%) were used as-received. Oligochitosan lactate (OC, MW 2.5k, \%DD 97\%) was purchased from Creative PEG Works. All aqueous solutions were prepared from Milli Q water.

\subsection{Methods}

\subsubsection{Synthesis of poly(ethylene oxide)-b-poly(acrylic acid)}

The poly(ethylene oxide)- $b$-poly(acrylic acid) DHBC (PEO- $b$ $\left.\mathrm{PAA}, \quad \mathrm{M}_{\mathrm{PEO}}=5000 \mathrm{~g} \cdot \mathrm{mol}^{-1}, \mathrm{M}_{\mathrm{PAA}}=1280 \mathrm{~g} \cdot \mathrm{mol}^{-1}\right)$ was synthesized according to the protocol reported by Reboul et al.[19] Briefly, this was achieved by atom-transfer radical polymerization (ATRP) of tert-butyl acrylate with $\omega$-bromide functionalized PEO macroinitiators $\left(\mathrm{M}_{\mathrm{w}}=5000 \mathrm{~g} \cdot \mathrm{mol}^{-1}\right)$ and subsequent deprotection reaction under acidic conditions. IR: $v / \mathrm{cm}^{-1} 1722(\mathrm{C}=\mathrm{O}), 1550$ (COO-), $1098\left(-\mathbf{O C H}_{2} \mathrm{CH}_{2}\right.$ - ether groups from PEO chains), $526(\mathrm{CBr})$. NMR ${ }^{1} \mathrm{H}$ : $(250 \mathrm{MHz}$; DMSO-d $)_{6}, 1.1 \mathrm{ppm}\left(6 \mathrm{H}, \mathrm{t},-\mathrm{O}-\mathrm{C}(\mathrm{O}) \mathrm{C}\left(\mathrm{CH}_{3}\right)_{2}-\right), 1.5 \mathrm{ppm}(82 \mathrm{H}$, br s, $\left.-\left(\mathrm{CH}_{2} \mathrm{CHC}(\mathrm{O}) \mathrm{OH}\right)_{1^{-}}\right), 2.3 \mathrm{ppm}(41 \mathrm{H}, \quad$ br $\mathrm{s}$, $\left.\left(\mathrm{CH}_{2} \mathrm{CHC}(\mathrm{O}) \mathrm{OH}\right)_{\mathrm{m}^{-}}\right), 3.25 \mathrm{ppm}\left(3 \mathrm{H}, \mathrm{s}, \mathrm{CH}_{3} \mathrm{OCH}_{2} \mathrm{CH}_{2-}\right), 3.5$ ppm $\left(448 \mathrm{H}\right.$, br s, $-\left(\mathrm{OCH}_{2} \mathrm{CH}_{2}\right)_{1^{-}}$and $4.05 \mathrm{ppm}(2 \mathrm{H}$, br s, $\left.\mathrm{CH}_{2} \mathrm{CH}_{2} \mathrm{OC}(\mathrm{O}) \mathrm{C}\left(\mathrm{CH}_{3}\right)_{2}-\right)$.

\subsubsection{Synthesis of bis(triethoxysilyl)benzene (BTEB)}

Following the procedure reported [20] in a $\mathrm{N}_{2}$ purged three-neck round-bottom flask with stirring bar, magnesium powder $(15 \mathrm{~g}$, $0.62 \mathrm{~mol}$ ) was dried before adding TEOS (450 mL, $2 \mathrm{~mol})$, dry THF $(250 \mathrm{~mL})$, and a few drops of dibromoethane. Then $\mathrm{p}$ dibromobenzene $(48 \mathrm{~g}, 0.20 \mathrm{~mol})$ in THF $(150 \mathrm{~mL})$ was added and the resulting solution was refluxed for another $2 \mathrm{~h}$, becoming dark purple. After the solution was cooled to room temperature overnight, the mixture was filtered on dry Celite and washed vigorously with pentane. The liquor was condensed by rotary evaporation and subjected to vacuum distillation to remove excess TEOS $\left(65{ }^{\circ} \mathrm{C}, 0.5\right.$ Torr), followed by product $\left(130{ }^{\circ} \mathrm{C}, 0.2\right.$ Torr), which appeared as a colorless oil (38 g, recovered yield $47 \%$ ). ${ }^{1} \mathrm{H} \mathrm{NMR}\left(400 \mathrm{MHz}, \mathrm{CDCl}_{3} / \mathrm{TMS}\right) \delta 7.68$ $(\mathrm{s}, 4 \mathrm{H}), 3.87(\mathrm{q}, 12 \mathrm{H}), 1.24(\mathrm{t}, 18 \mathrm{H})$.

\subsubsection{Synthesis of PICPMO}

Typically, $178.4 \mathrm{mg}$ of OC was mixed with $250.7 \mathrm{mg}$ of PEO$b$-PAA in $6.8 \mathrm{~mL}$ of water at room temperature. The solution $\mathrm{pH}$ was reduced to about 2 by addition of a $3 \mathrm{M}$ aqueous $\mathrm{HCl}$ solution and $893 \mu \mathrm{L}$ of BTEB was added. The $\mathrm{pH}$ was kept at 2 , under vigorous stirring at $30{ }^{\circ} \mathrm{C}$ for an hour and at $50{ }^{\circ} \mathrm{C}$ for another hour to promote hydrolysis of the organosilane. After completion of BTEB hydrolysis, the solution $\mathrm{pH}$ was increased to 6.5 by addition of $3 \mathrm{M} \mathrm{NaOH}$ solution. This final $\mathrm{pH}$ value simultaneously induces DHBC-OC complexation and polycondensation of the organosilicate species. A precipitate was observed immediately upon increasing the $\mathrm{pH}$, and the solution was left under stirring $\left(100 \mathrm{~min}^{-1}\right)$ for $24 \mathrm{~h}$ at $30{ }^{\circ} \mathrm{C}$. Finally, the precipitate was recovered by centrifugation $(10000$ $\min ^{-1}, 15 \mathrm{~min}$ ) and air-dried at $40{ }^{\circ} \mathrm{C}$ for $48 \mathrm{~h}$, yielding a beige powder. PICPMO materials were prepared using 2 wt $\%$ of DHBC, with a molar ratio between polymer AA units and nitrogen $\mathrm{OC}(\mathrm{N}: \mathrm{AA})$ of 1 and an equimolar ratio between ethylene oxide units and $\mathrm{Si}(\mathrm{OE}: \mathrm{Si}=1)$

\subsubsection{Washing of PICPMO materials to remove PIC}

The general washing procedure involved addition of the dried PICPMO material $(50 \mathrm{mg})$ to a $\mathrm{NaCl}$ aqueous solution $(5 \mathrm{~mL}, 1$ $\mathrm{M})$ at $\mathrm{pH}$ 2, adjusted with a $\mathrm{HCl}(3 \mathrm{M})$ solution, at $25^{\circ} \mathrm{C}$ to destabilize the PIC complex. After 4 hours under stirring at 250 $\mathrm{min}^{-1}$, the resulting solid was collected by centrifugation (10000 $\min ^{-1}, 10 \mathrm{~min}$ ) and washed thoroughly with water. Finally, the product was dried in an oven at $40^{\circ} \mathrm{C}$ for $48 \mathrm{~h}$.

\subsection{Characterization}

Dynamic Light Scattering (DLS) experiments were carried out on a Malvern 4800 Autosizer (Malvern Instruments, UK) equipped with a $50-\mathrm{mW}$ laser operating at $532 \mathrm{~nm}$. The experiments were performed at $25 \pm 1^{\circ} \mathrm{C}$ at a scattering angle of $90^{\circ} \mathrm{C}$. FTIR spectra were obtained using a PerkinElmer FT-IR Spectrum BX spectrophotometer equipped with a Gladia-ATR accessory. Thermogravimetric analyses (TGA) were performed on a Netzsch TG $209 \mathrm{C}$ instrument using a heating rate of $10{ }^{\circ} \mathrm{C} \mathrm{min}-1$ under an air flow of $20 \mathrm{~mL} \mathrm{~min}^{-1}$ up to $900{ }^{\circ} \mathrm{C}$. The mass percentage of silica $\left(\% \mathrm{~m} \mathrm{SiO}_{2}\right)$ was evaluated from the residual mass at $900^{\circ} \mathrm{C}$. Given the chemical structure of BTEB, we assume that each silicon atom is associated with three carbon atoms (assuming complete hydrolysis and quantitative retention of phenyl bridges within the PICPMO, as verified below by NMR). This enables the mass percentage of carbon present in the walls to be deduced $\left(\% \mathrm{~m}_{\mathrm{C}}\right.$ wall $)$. Elemental analyses of nitrogen and carbon were performed on an Interscience Flash EA 1112 series (Thermo Finnigan). The nitrogen analyses were used to determine the mass percentage of oligochitosan in the 
materials $\left(\% \mathrm{~m}_{\mathrm{OC}}\right)$, which in turn was used to calculate the mass percentage of carbon originating from $\mathrm{OC}\left(\% \mathrm{~m}_{\mathrm{COC}}\right)$. Finally, the carbon content was used to calculate the DHBC weight percentage $\left(\% \mathrm{~m}_{\mathrm{DHBC}}\right)$ as follows:

$$
\begin{gathered}
\% C=\% m_{C P H E}+\% m_{C O C}+\% m_{C D H B C} \\
\% C=\% m_{C P H E}+\left(\% m_{O C} * \% m_{C_{O C}}\right)+\left(\% \boldsymbol{m}_{D H B C} * \%_{C_{D H B C}}\right) ; \\
\% N=\left(\% m_{O C} * \% m_{N_{O C}}\right) ;
\end{gathered}
$$

where $\% m_{C P H E}, \% m_{C_{O C}}, \% m_{C_{D H B C}}$ and $\% m_{N_{O C}}$ respectively refer to the mass content of $\mathrm{C}$ in the bridging phenylenes, $\mathrm{OC}$ and in the DHBC, and the mass content of $\mathrm{N}$ in OC. The small and wide angle X-ray scattering (SWAXS) experiments were conducted using a Guinier-Mering setup with a 2D image plate detector. The X-ray source was a molybdenum anode, which delivered a high-energy monochromatic beam $(\lambda=0.71 \AA$, $\mathrm{E}=17.4 \mathrm{keV}$ ), providing structural information over scattering vectors $q$ ranging from 0.02 to $2.5 \AA^{-1}$. The region between the sample and image plate was purged with flowing helium, to avoid air adsorption. The data acquisition time was $1800 \mathrm{~s}$ and the glass capillaries used to hold the samples (Higenberg) had a thickness of $2 \mathrm{~mm}$. The image azimuthal average was determined using FIT2D software from ESRF (France), and data corrections and radial averaging were performed via standard procedures. Transmission electron microscopy (TEM) images were collected on a JEOL 1200 EX II operating at 120 $\mathrm{kV}$ on microtomed samples ( $70 \mathrm{~nm}$ thickness). ${ }^{29} \mathrm{Si}$ and ${ }^{13} \mathrm{C}$ solid-state NMR spectra were obtained on a Bruker DSX 300 $\mathrm{MHz}$ spectrometer by using cross-polarization and magic-angle spinning techniques (CP-MAS).

\section{Results and Discussion}

Despite the advantages of traditional approaches using alkyl ammonium salts for preparing PMOs, such strategies also have well-known disadvantages, including the loss of the structuring agent during processing and the relatively small size of the pores. Many of these disadvantages are overcome by the use of polyionic complex (PIC) micelles as structuring agents. In our study, PIC micelles are assemblies formed from doublehydrophilic block copolymers, corresponding to poly(ethylene oxide)-b-poly(acrylic acid) $\left(\mathrm{M}_{\mathrm{PEO}}=5000 \mathrm{~g} \cdot \mathrm{mol}^{-1}\right.$, and $\mathrm{M}_{\mathrm{PAA}}=$ 1280 g. mol ${ }^{-1}$ ) and oligochitosan (OC) (Fig.1).
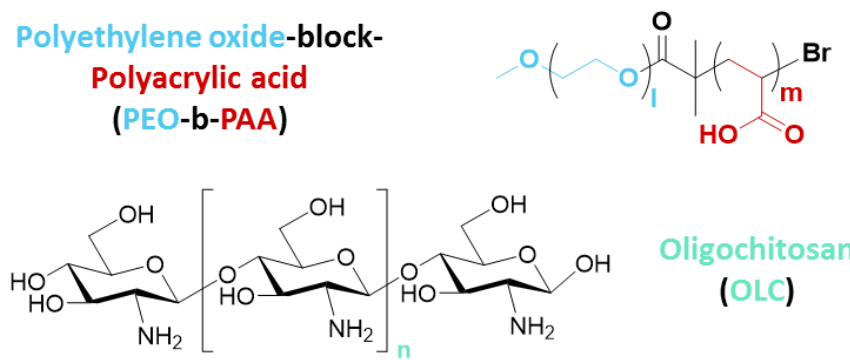

Fig. 1. Chemical structure of PEO- $b$-PAA DHBC and OC

PEO- $b$-PAA is soluble in water, but within an appropriate $\mathrm{pH}$ range, and in the presence of OC, PIC micelles are obtained as shown by the dynamic light scattering data in Fig. 2. The high scattering intensity indicated that micellization occurred between $\mathrm{pH}$ 4-7.5 while their dissociation occurred outside of this $\mathrm{pH}$ range. This is due to the $\mathrm{pKa}$ of the polyacid $\left(\mathrm{pK}_{\mathrm{a}}=4\right)$ and polybase $\left(\mathrm{pK}_{\mathrm{a}}=6.5\right)$, which respectively produce negatively and positively charged species at $\mathrm{pH} 4-7.5$, thus promoting their association by electrostatic interactions. DLS data reveal that PIC micelles have a maximum hydrodynamic diameter of around $35 \mathrm{~nm}$ at $\mathrm{pH}$, as typically obtained with PEO- $b$-PAA of similar block lengths.[10,19] Hence, a pH value in this welldefined $\mathrm{pH}$ domain was chosen for preparing mesostructured PMO materials.

Fig. 2. Scattered light intensity of OC and PEO- $b$-PAA in

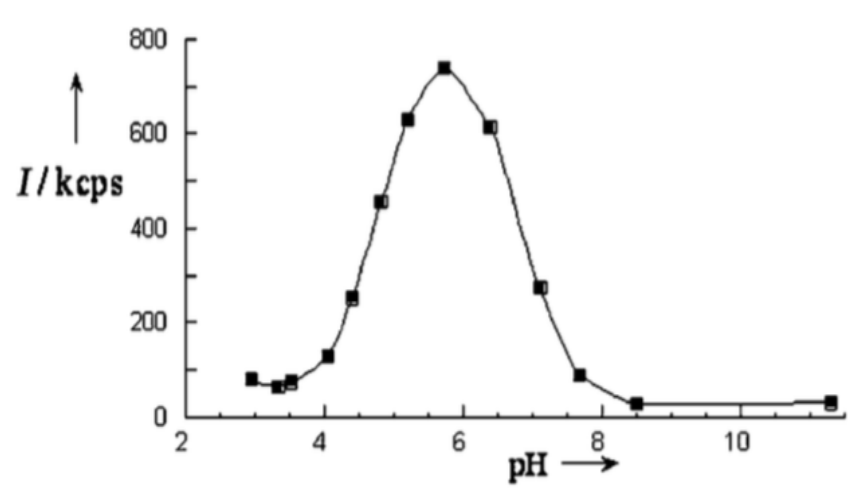

water as a function of $\mathrm{pH}[10]$

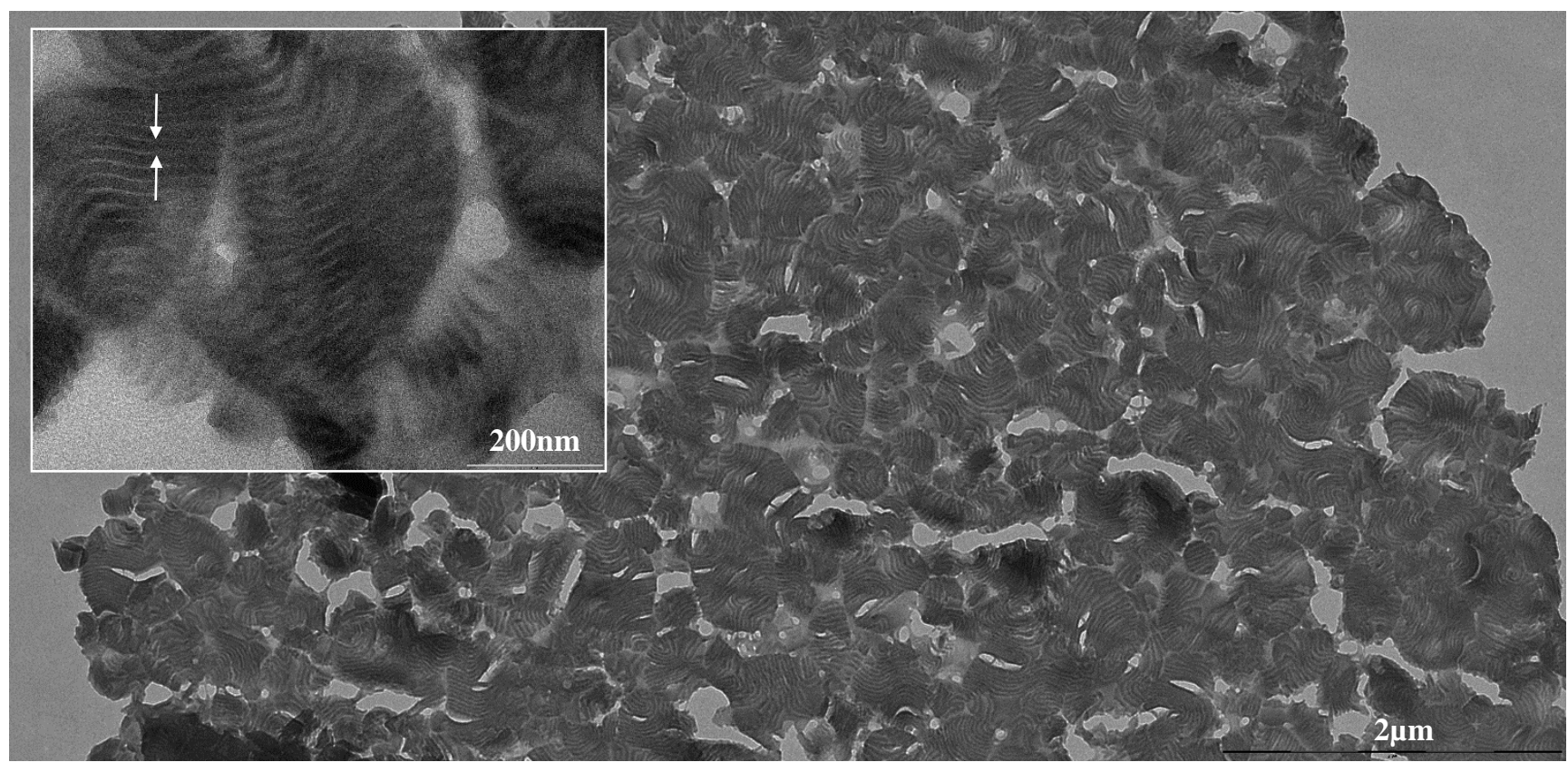

Fig. 3 Transmission Electron Microscopy of the lamellar mesostructured hybrid PICPMO 
Such PIC micelles have already been shown to successfully template the formation of ordered mesoporous silica [12,13]. As with classical structuring agents, PIC micelles offer the opportunity to easily tune the mesostructure of the materials by modulating parameters such as $\mathrm{pH}$, concentration, composition of the synthesis medium, etc The synthesis of hybrid materials using PIC micelle systems occurs in two steps. First, the PAA$b$-PEO and the OC are dissolved in an aqueous solution. BTEB is then added, leading to a diphasic system and the $\mathrm{pH}$ is adjusted to a value of 2 for one hour at $30^{\circ} \mathrm{C}$ and another hour at $50^{\circ} \mathrm{C}$ to promote BTEB hydrolysis. Secondly, the hybrid material is synthesized by increasing the $\mathrm{pH}$ of the mixture to 6.5 at $30^{\circ} \mathrm{C}$ by adding small quantities of a $3 \mathrm{M} \mathrm{NaOH}$ solution; this specific $\mathrm{pH}$ is situated within the range at which micellization occurs. After $24 \mathrm{~h}$, a precipitate is recovered and dried at $40{ }^{\circ} \mathrm{C}$ for $48 \mathrm{~h}$.

The typical structuring of organosilica that can be achieved with PAA- $b$-PEO/OC PIC micelles is clearly revealed by the crosssectional TEM images shown in Fig. 3. The micrographs show that the formation of hybrid mesostructured materials can be mediated by the DHBC/OC acting as a structure directing agent. Under the conditions employed in this work, the mesostructured PMO consists of agglomerated spheroidal particles of PMO lamellae. This result suggests that the PEO block is capable of interacting with organosilica precursors such as BTEB, despite the hydrophobic nature of the aromatic moiety, leading to the formation of hybrid micelle-organosilica mesophases.

The SWAXS spectrum of the phenylene-PMO material is shown in Fig.4. The scattered intensity displays two broad peaks at q-values of $0.424 \mathrm{~nm}^{-1}$ and $0.88 \mathrm{~nm}^{-1}$ (with an inter-reticular ratio of 2), consistent

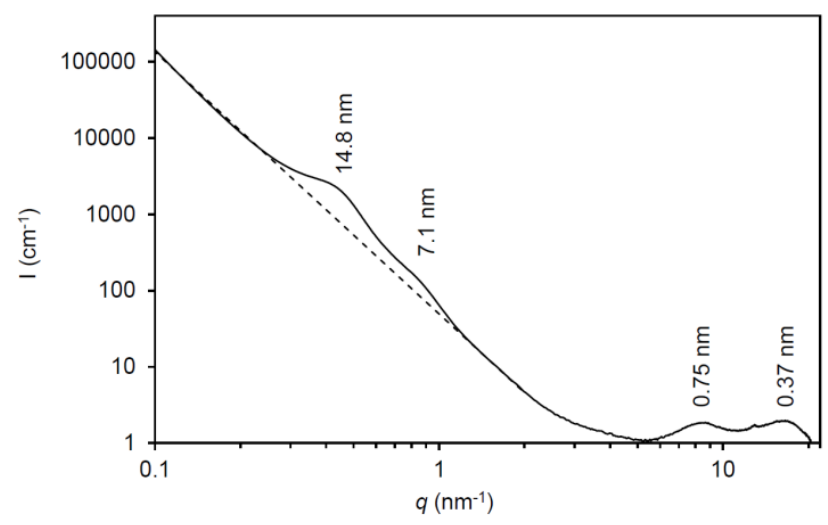

Fig. 4 SAXS and WAXS profile of unwashed PICPMO

with the "signature" of a lamellar structure. The pseudo-Bragg peak obtained from the q-values of $0.42 \mathrm{~nm}^{-1}$ corresponds to a distance of $14.8 \mathrm{~nm}$ while that at $0.88 \mathrm{~nm}^{-1}$ corresponds to the second harmonic, consistent with medium-range structural periodicity. These data are consistent with the $15 \mathrm{~nm}$ interlamellae distance deduced from the TEM image (see the white arrows in Fig. 3). It was not possible to obtain meaningful poregeometry data from the $\mathrm{N}_{2}$ adsorption-desorption isotherms of the washed material, with only small specific volumes of $\mathrm{N}_{2}$ sorbed during dosing. The correspondingly low apparent specific surface areas and pore volumes are attributed to the retention of some organic template species within the pores, and also to some collapse of the lamellar structure upon drying and degassing before the sorption analysis. In addition, the background slope of -3.4 on the log-log plot in Fig. 4 (I(q) $\alpha$ q 3.4 as indicated by the dashed line) indicates that the particle surface is rough on the length scale probed in this study. Two additional peaks are also observed at higher q, corresponding to correlation distances of 0.76 and $0.38 \mathrm{~nm}$, which are assigned to molecular-scale periodicities within the lamellae arising from ordering of the $\mathrm{Si}_{-} \mathrm{C}_{6} \mathrm{H}_{4}-\mathrm{Si}$ moieties [14].

Solid-state ${ }^{13} \mathrm{C}$ and ${ }^{29} \mathrm{Si}$ NMR measurements of the washed PMOs were performed to verify the composition and structure of the covalently-bonded phenylene-bridging groups in the framework. The ${ }^{13} \mathrm{C}$ cross polarization (CP) MAS NMR spectrum, shown in Fig. 5(a), displays a single peak at 133.7 ppm corresponding to the covalent bond between the aryl carbon and the silicon atoms, which indicates that the Si-phenyl moieties are intact in the hydrolysed and condensed silicate network. A distinct single peak around $69.2 \mathrm{ppm}$ attributed to the $-\mathrm{CH}_{2}$ groups of the PEO suggests that the DHBC is also incorporated into the silylated matrix during

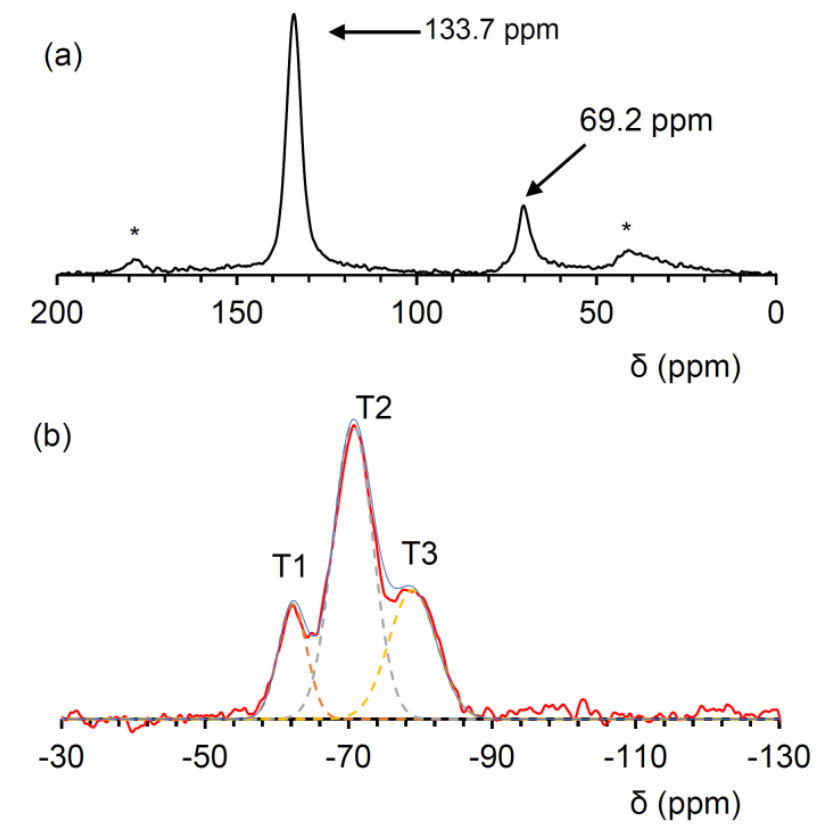

Fig. 5 (a) ${ }^{13} \mathrm{C}$ CPMAS and (b) ${ }^{29} \mathrm{Si}$ MAS NMR spectra of washed PICPMO

material preparation and is not readily removed by the simple washing procedure employed here. The resonances marked with asterisks are due to spinning sidebands.

The ${ }^{29} \mathrm{Si}$ MAS NMR spectrum (Fig. 5 (b)) revealed the characteristic signals of the phenylene-bridged $\mathrm{Si}$ atoms assigned to $\mathrm{C}-\mathrm{Si}(\mathrm{OSi})_{3}(\mathrm{~T} 3,-81 \mathrm{ppm}), \mathrm{C}-\mathrm{Si}(\mathrm{OSi})_{2}(\mathrm{OH})(\mathrm{T} 2,-72$ $\mathrm{ppm})$, and $\mathrm{C}-\mathrm{Si}(\mathrm{OSi})(\mathrm{OH})_{2}(\mathrm{~T} 1,-62 \mathrm{ppm})$. No peaks associated with $\mathrm{Q}$ species were observed, which confirms that the $\mathrm{C}-\mathrm{Si}$ bonds are stable during the preparation and washing of the material. The integrated area under the Tn peaks (derived by least-squares fitting) was used to determine the extent of condensation in the PICPMO, with an equivalent stoichiometry of $\mathrm{R}-\mathrm{SiO}_{\mathrm{x}}(\mathrm{OH})_{3 \mathrm{x}-2}$ (where $\mathrm{x}=1.06$ ) being observed. This reflects incomplete condensation within the system, together with the presence of surface silanol groups for possible further postfunctionalization.

FTIR spectroscopy was used to further characterize the framework structure of the nanohybrid, as shown in Fig. 6. The antisymmetric stretching mode of $\mathrm{Si}-\mathrm{O}-\mathrm{Si}$ at about $1090 \mathrm{~cm}^{-1}$ is consistent with the formation of siloxane networks in the framework of the PICPMO product. The $\mathrm{C}-\mathrm{H}$ out-of-plane mode at about $773 \mathrm{~cm}^{-1}$ is associated with the phenylene group. Moreover, the aromatic ring mode at $810 \mathrm{~cm}^{-1}$ and the Si-C 
vibrations at $1153 \mathrm{~cm}^{-1}$ are clearly observed in the spectrum, consistent with the presence of phenylene bridging groups covalently incorporated within the framework.

Furthermore, according to Lin et al[21], the $640 \mathrm{~cm}^{-1}$ peak arises from ordering of the phenylene rings. A decrease in ordering results in an increase in the intensity of the band. This peak is essentially absent in the spectrum of the as-prepared (unwashed) material, suggesting that washing may lead to a decrease in the ordering of the phenylene rings $(\pi-\pi$ stacking). This phenomenon might reflect an increase in the extent of framework cross-linking and rigidity during washing, and a corresponding decrease in the ability of the framework to support $\pi-\pi$ stacking.

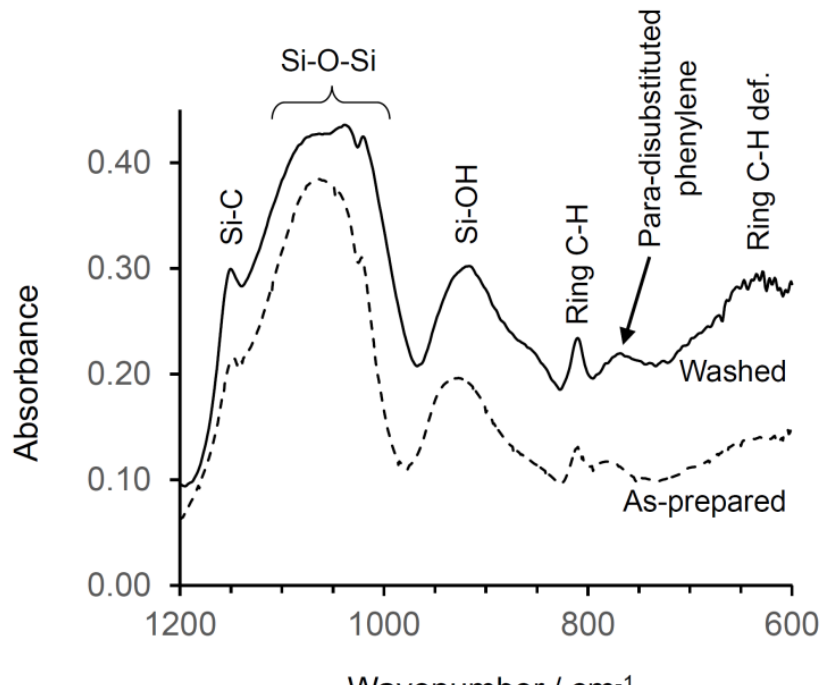

Fig. 6 IR spectrum (600 to $1200 \mathrm{~cm}-1)$ of washed (solid line) and as-prepared (dashed line) PICPMO

The thermal behavior of the as-prepared PICPMO was investigated by thermogravimetric analysis, as shown in Fig. 7. The TGA profile exhibits a first weight loss between 30 and $120{ }^{\circ} \mathrm{C}$ due to the removal of physisorbed water, which is complete at about $200^{\circ} \mathrm{C}$. Above $120^{\circ} \mathrm{C}$, several phenomena are superimposed, including decomposition of the organic PIC, the degradation of the phenylene bridges and also the condensation of hydroxyl groups to form siloxane bridges [22]. The relatively high thermal stability of the PICPMO is evident from the gradual decomposition of the phenylene bridges at temperatures above $300{ }^{\circ} \mathrm{C}$ (presumably occurring along with decomposition of DHBC and OC), which continued until $650{ }^{\circ} \mathrm{C}$.

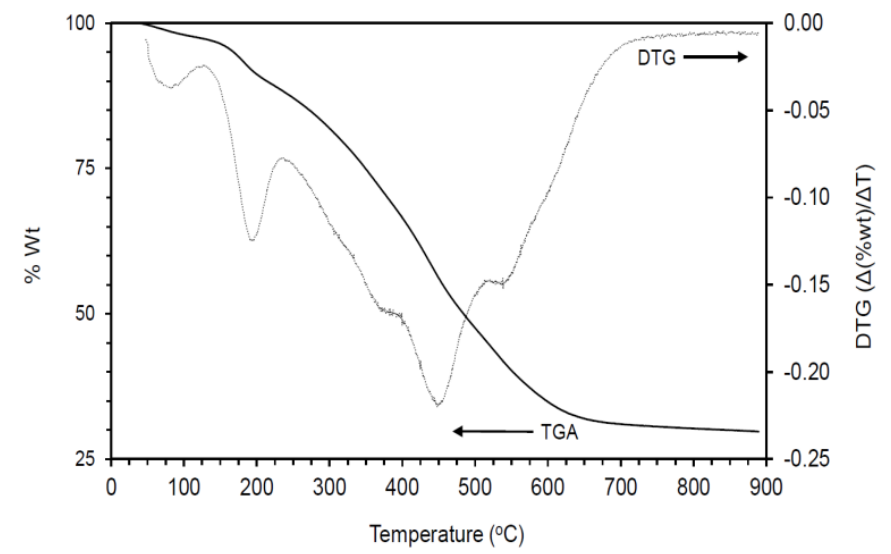

Fig. 7 Thermogravimetric analysis of as-prepared PICPMO material (containing template)
The composition of the as-synthesized PICPMO material (dried at $40{ }^{\circ} \mathrm{C}$ for $48 \mathrm{~h}$ ) was determined from thermogravimetric and elemental analysis data, following the procedure described in the Experimental section. The mass fractions (wt \%) of DHBC, OC, phenylene bridges and physisorbed/chemisorbed water

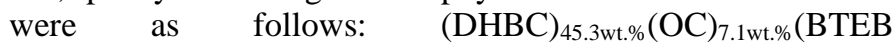
wall $)_{44.7 \mathrm{wt} \%}\left(\mathrm{H}_{2} \mathrm{O}\right)_{2.9 \mathrm{w} \%}$. The composition can be described by two key molar ratios, N:AA (0.33) and EO:Si (1.65). The first corresponds to the complexation between $\mathrm{N}$ atoms from $\mathrm{OC}$ and the acrylic acid functions of the DHBC, while the second reflects the interaction between the ethylene oxide functions of the DHBC and the silanes. The low N:AA value, which is less than the initial ratio of 1.0, indicates that a significant fraction of the $\mathrm{OC}$ is not retained within the as-prepared material via electrostatic interactions with DHBC. In addition, the high EO:Si ratio confirms that ethylene oxide units are retained within the structure via hydrogen bonding with the silylated precursor (as previously reported by Gerardin et al. for TEOSderived materials $[12,13]$, facilitating the structuring observed by TEM (Fig. 3).

\section{CONCLUSION}

In summary, nanostructured PICPMOs with an ordered lamellar structure were shown to be produced from polysilylated precursors, using polyion complex micelles formed from DHBC polymers as new structuring agents for organosilica systems. Our strategy for varying the nature and the properties of the porous structure is based on a careful control of the synthesis parameters, including $\mathrm{pH}$, temperature, concentration and composition. Modulation of the mesostructure will enable controlling material properties for specific end-user applications, with applications in nanomedicine currently being explored.

Although in this work we describe the synthesis of lamellar materials, in future papers we will demonstrate the preparation of mesoporous 2D hexagonal or cubic PICPMO systems, with adjustable porosity characteristics.

\section{COMPLIANCE WITH ETHICAL STANDARDS}

Conflict of interest: The authors declare that they have no competing interests.

\section{Acknowledgement}

The authors acknowledge Dr Philippe Gaveau (Institut Charles Gerhardt Montpellier) for solid state NMR experiments, and Akira Ishii and Professor Masafumi Unno (Department of Chemistry and Chemical Biology, Graduate School of Science and Technology, Gunma University, Japan) for their contribution to this work. We thank the French Agence Nationale de la Recherche for funding of the MESOPIC Project (2015-2019), No. ANR-15-CE07-0005. 


\section{REFERENCES}

1. Inagaki S, Guan S, Fukushima Y, Ohsuna T, Terasaki O (1999) Novel Mesoporous Materials with a Uniform Distribution of Organic Groups and Inorganic Oxide in Their Frameworks. Journal of the American Chemical Society 121 (41):9611-9614

2. Asefa T, MacLachlan MJ, Coombs N, Ozin GA (1999) Periodic mesoporous organosilicas with organic groups inside the channel walls. Nature 402 (6764):867-871

3. Melde BJ, Holland BT, Blanford CF, Stein A (1999) Mesoporous sieves with unified hybrid inorganic/organic frameworks. Chemistry of Materials 11 (11):3302-3308

4. Hoffmann F, Cornelius $M$, Morell J, Fröba M (2006) Silica-Based Mesoporous Organic-Inorganic Hybrid Materials. Angewandte Chemie 45 (20):3216

5. Croissant JG, Cattoën $X$, Wong Chi Man $M$, Durand J-O, Khashab NM (2015) Syntheses and applications of periodic mesoporous organosilica nanoparticles. Nanoscale 7 (48):20318-20334

6. Du X, Li X, Xiong L, Zhang X, Kleitz F, Qiao SZ (2016) Mesoporous silica nanoparticles with organo-bridged silsesquioxane framework as innovative platforms for bioimaging and therapeutic agent delivery. Biomaterials 91:90-127

7. Zhu H, Jones DJ, Zajac J, Roziere J, Dutartre R (2001) Periodic large mesoporous organosilicas from lyotropic liquid crystal polymer templates. Chemical Communication - Royal Society of Chemistry:2568-2569

8. Hu Y, Qian K, Yuan P, Wang Y, Yu C (2011) Synthesis of large-pore periodic mesoporous organosilica. Materials Letters 65 (1):21-23

9. Yang $Y$, Niu $Y$, Zhang J, Meka AK, Zhang $H, X u C$, Lin CXC, Yu M, Yu C (2015) Biphasic Synthesis of Large-Pore and Well-Dispersed Benzene Bridged Mesoporous Organosilica Nanoparticles for Intracellular Protein Delivery. Small 11 (23):27432749

10. Baccile N, Reboul J, Blanc B, Coq B, LacroixDesmazes $P$, In M, Gérardin C (2008) Ecodesign of Ordered Mesoporous Materials Obtained with Switchable Micellar Assemblies. ANIE Angewandte Chemie International Edition 47 (44):8433-8437

11. Bucur CB, Sui Z, Schlenoff JB (2006) Ideal mixing in polyelectrolyte complexes and multilayers: entropy driven assembly. Journal of the American $\begin{array}{lll}\text { Chemical Society } 128 & \text { (42):13690-13691. }\end{array}$ doi:10.1021/ja064532c
12. Molina E, Warnant J, Mathonnat M, Bathfield $M$, In $M$, Laurencin $D$, Jerome $C$, Lacroix-Desmazes P, Marcotte N, Gerardin C (2015) Drug-Polymer Electrostatic Complexes as New Structuring Agents for the Formation of Drug-Loaded Ordered Mesoporous Silica. Langmuir 31 (47):12839-12844

13. Houssein D, Warnant J, Molina E, Cacciaguerra T, Gérardin C, Marcotte N (2017) Mesoporous silica templated by polyion complex micelles: A versatile approach for controlling the mesostructure. Microporous and Mesoporous Materials 239:244252

14. Inagaki S, Guan S, Ohsuna T, Terasaki O (2002) An ordered mesoporous organosilica hybrid material with a crystal-like wall structure. Nature 416 (6878):304-307. doi:10.1038/416304a

15. Huybrechts W, Mali G, Kustrowski P, Willhammar T, Mertens M, Bals S, Van Der Voort P, Cool P (2016) Post-synthesis bromination of benzene bridged PMO as a way to create a high potential hybrid material. Microporous and Mesoporous Materials 236:244-249

16. Hao N, Yang Y, Wang H, Webley PA, Zhao D (2010) Synthesis of large-pore phenyl-bridged mesoporous organosilica with thick walls by evaporation-induced self-assembly for efficient benzene adsorption. Journal of colloid and interface science 346 (2):429-435

17. Mandal M, Kruk M (2010) Versatile approach to synthesis of 2-D hexagonal ultra-large-pore periodic mesoporous organosilicas. Journal of Materials Chemistry 20 (35):7506-7516

18. Moura CP, Vidal CB, Barros AL, Costa LS, Vasconcellos LC, Dias FS, Nascimento RF (2011) Adsorption of BTX (benzene, toluene, o-xylene, and p-xylene) from aqueous solutions by modified periodic mesoporous organosilica. Journal of colloid and interface science 363 (2):626-634

19. Reboul J, Nugay $T$, Anik N, Cottet $H$, Ponsinet V, In M, Lacroix-Desmazes P, Gerardin C (2011) Synthesis of double hydrophilic block copolymers and induced assembly with oligochitosan for the preparation of polyion complex micelles. Soft Matter 7 (12):5836-5846. doi:10.1039/c1sm05230f 20. Shea KJ, Loy DA, Webster O (1992) Arylsilsesquioxane gels and related materials. New hybrids of organic and inorganic networks. Journal of the American Chemical Society 114 (17):67006710

21. Lin F, Meng X, Mertens $M$, Cool P, Van Doorslaer $S$ (2014) Probing framework-guest interactions in phenylene-bridged periodic mesoporous 
organosilica using spin-probe EPR. Physical Chemistry Chemical Physics 16 (41):22623-22631. doi:10.1039/c4cp03778b

22. Zhuravlev $L(2000)$ The surface chemistry of amorphous silica. Zhuravlev model. Colloids and Surfaces A: Physicochemical and Engineering Aspects 173 (1):1-38 